\title{
Cycle Oriented Quality Management at the Interface of Product Development and Production Planning
}

\author{
Jonas Koch, Josef Greitemann, Christian Plehn, and Gunther Reinhart \\ Institute for Machine Tools and Industrial Management (iwb), \\ Technische Universität München, Munich, Germany
}

\begin{abstract}
During all phases in the product life cycle quality is a key influencing factor. The earlier a high quality level reached during the product lifecycle, the lower the amount of quality deviations, required changes, and the occurrence of non-conformance costs throughout mass production. Already in the prototype phase, an efficient and effective quality control loop is an important enabler for achieving a high level of product quality. This includes a quality process and specified interfaces to product development, production planning and overall quality management. Presenting an approach for the development of such a quality control loop including interfaces to associated processes in product development, production planning and quality management as well as a first examination of affected process parts in production planning is subject of this paper.
\end{abstract}

Keywords: Product quality, quality control loop, prototype phase, ramp-up, product lifecycle, reconfiguration, manufacturing resources.

\section{Introduction}

\subsection{Quality in Context of the Product Lifecycle}

Quality is a key influencing factor on product lifecycles [1] - from the very beginning during the product development phase through the prototype phase, ramp-up (i.e. pre-series, pilot series, run-up) and mass production until product phase out (see fig. 1) [2,3]. As part of the "magic triangle of production" - costs, time and quality - quality represents one of the essential business success criteria for manufacturing companies [4].

Based on the "rule of ten", saying that costs to find and repair defects raise by the factor of ten for each level of completion (e.g. completion of development and design, completion of production planning) reached during engineering and manufacturing of a product $[5,6]$, achieving a sufficient level of product quality in early product lifecycle phases significantly improves the subsequent occurrence of non-conformance costs during later phases such as mass-production. Non-conformance costs arise from e.g. rework due to quality deviations or necessary reconfigurations of the product or the production structure. $[7,8]$

Within the product lifecycle, one major phase before the start of production (SOP) is the so-called prototype phase, the direct precursor of the production ramp-up. 


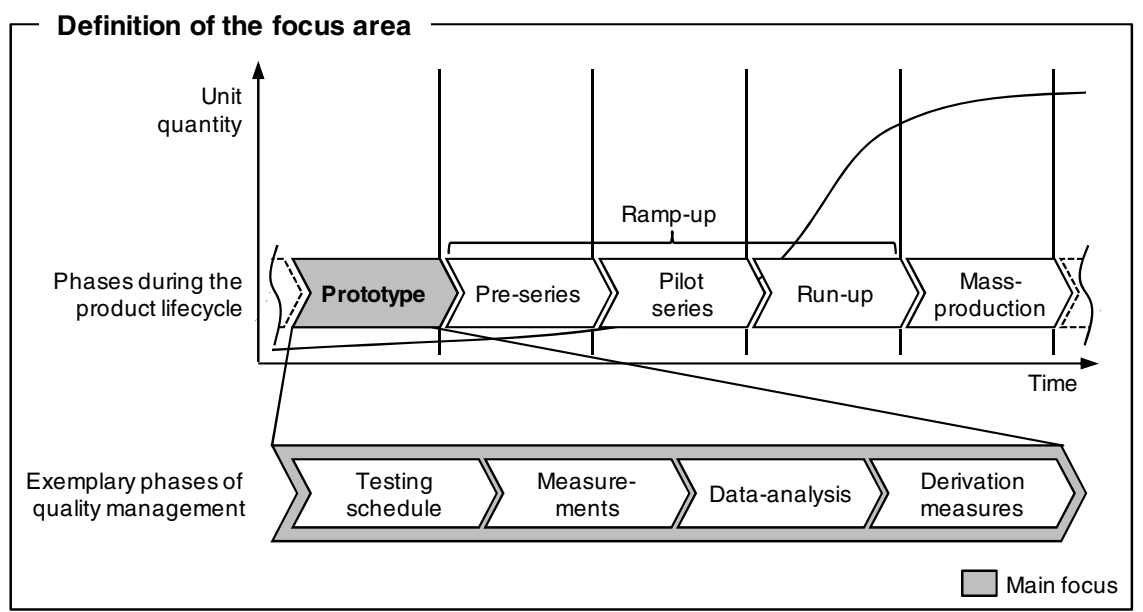

Fig. 1. Definition of the focus area [cf. 2,3]

The prototype phase is characterized by low production volumes, utilization of preseries manufacturing resources and evaluation of process capabilities for product assembly [9]. The process capabilities are usually enhanced during the prototype phase to achieve higher levels of quality, lead time and costs which are close to those required during mass production. Comparable to the more general stage-gate-process [10], achievement of these levels marks the readiness to shift from the prototype phase to the production ramp-up phase from a manufacturing point of view [cf. 3].

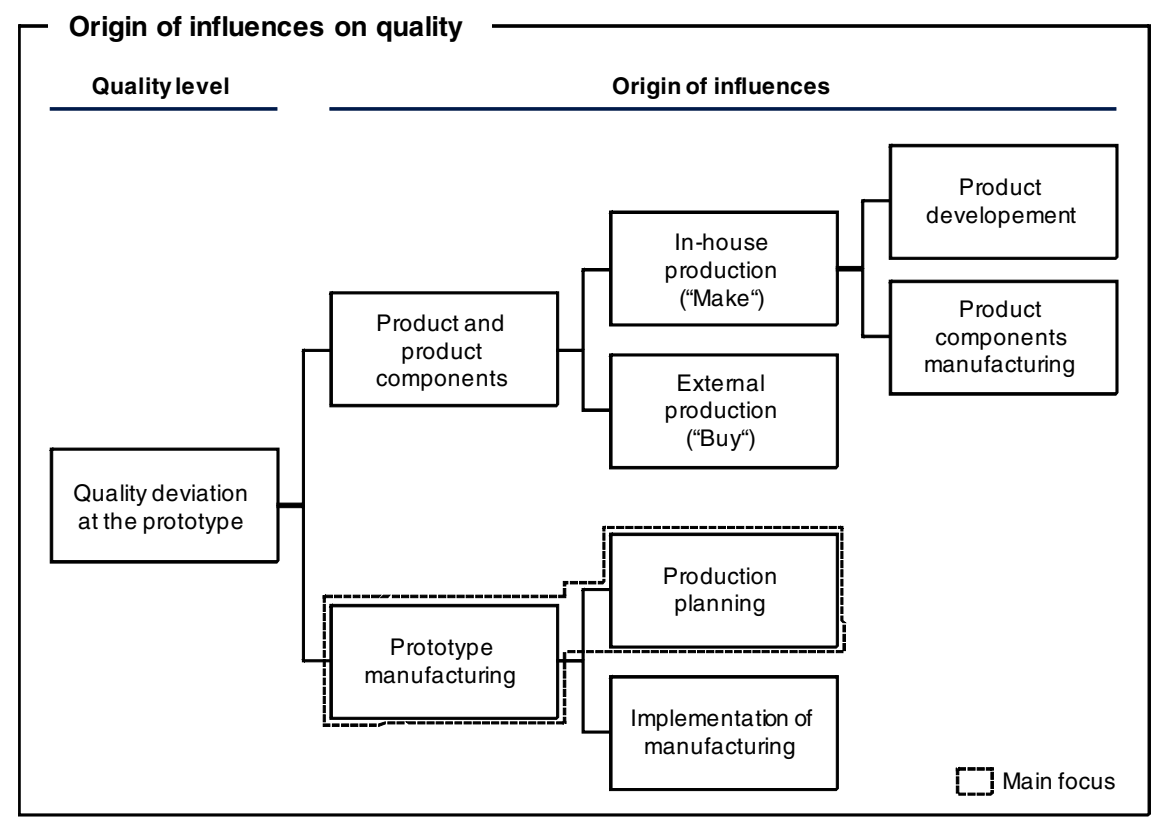

Fig. 2. Causes for quality deviations 


\subsection{Determination of Quality During Prototype Phase}

The prototype's quality level is determined by influences related to both, product and product components as well as manufacturing, covering production structure, manufacturing resources, processes and configurations (see fig. 2) [11-13].

Product and Product Components. Influences related to product and product components result from e.g. product specifications or the quality of supplier parts. In case of product specifications not suitable for assembly or insufficient manufacturing quality of supplier parts, resulting influences show a direct negative impact on prototype quality. Controlling such influences requires a cooperative elaboration of solutions together with mainly suppliers in case of "buy-components" or with mainly product development and, if needed, manufacturing in case of "make-components". [14]

Prototype Manufacturing. Influences related to manufacturing processes and production configuration result from e.g. process planning, process requirements, process instabilities, sequence of operations or the configuration of manufacturing resources. For instance, incorrect process planning or inappropriate configurations of manufacturing resources cause negative impacts on the prototype quality. Controlling those influences requires a cooperative elaboration of measurements together with e.g. production planning or shop floor employees. $[15,16]$

The abovementioned influences on prototype quality manifest themselves in measurable quality deviations such as exceeded tolerances or high process variability. The occurrence of these effects determines the level of quality of prototypes as it is understood within this paper.[17] Hence, the detection and evaluation of measurable effects as well as identification and controlling of causative influences are key levers for an improved level of quality of the produced prototypes.

Besides the negative impact on prototype quality, the aforementioned influences can also delay the prototype phase, increase the required number of prototypes, cause additional effort in product development for changes and thus raise overall costs of this phase. In the worst case, consequences of quality deviations are underestimated or the quality deviations remain undetected. That can cause costly adaptations and changes of e.g. the production structure, processes or manufacturing resources during ramp-up or even mass-production phase cumulating in increased non-conformance costs. [6]

\subsection{Quality Management During Prototype Phase}

In order to prevent such major incidences for manufacturing companies, quality management $(\mathrm{QM})$ is established as a function/department to, among others, develop, implement and improve processes for detection and evaluation of occurring quality deviations during the product lifecycle phases. This is a basis for continuous product, production and therefore quality improvements [18]. Focusing on the activities during the prototype phase and also on the interfaces to previous and subsequent phases of 
the product lifecycle, QM is responsible for ensuring a sufficient level of quality of prototypes. This is done by implementing adequate quality control loops and quality processes which are aligned and connected with associated processes in product development, production planning and overall QM. As mentioned above, the main task of quality processes during the prototype phase is the detection and evaluation of deviations from defined quality levels, identification of the causative influence and the consequent initiation of the development of improvement measures (see fig. 3). Depending on the respective origin of the influence, improvement measures have to be elaborated either by product development, production planning or suppliers.

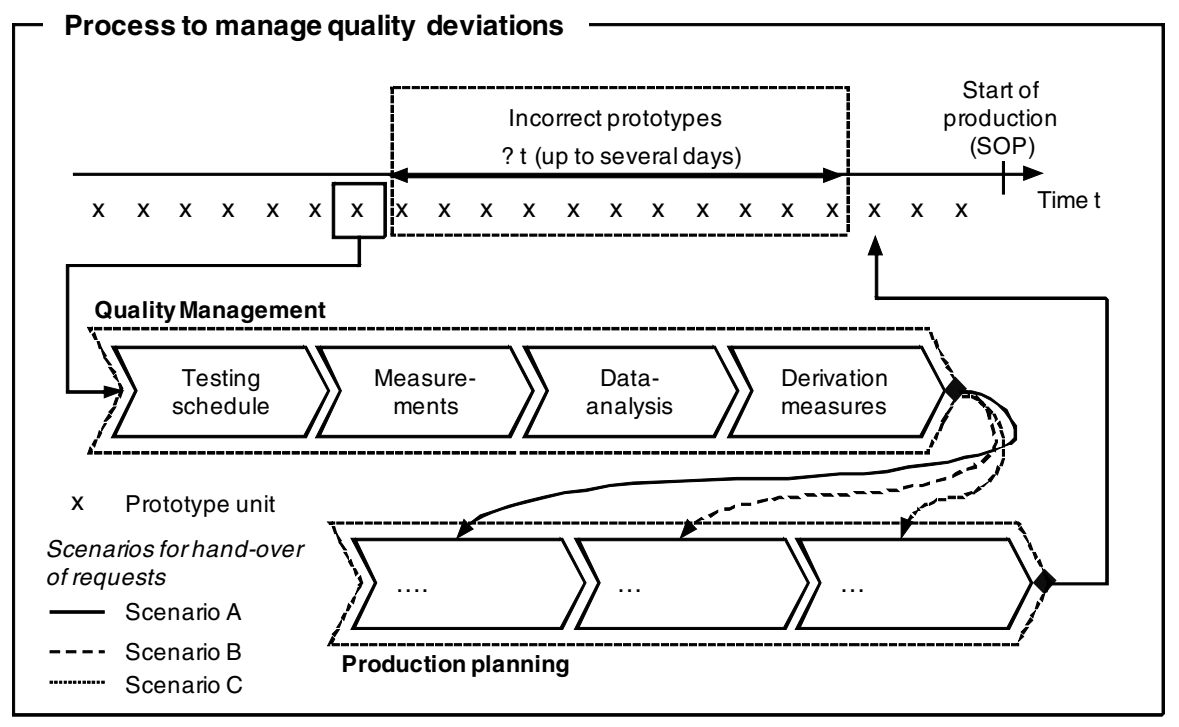

Fig. 3. Process to manage quality deviations

\subsection{Problem Statement}

The definition of an efficient and effective quality control loop is one of the key challenges for improving the quality level of prototypes and reducing overall nonconformance costs [cf. 19]. Such a quality control loop includes a quality process for the prototype phase with defined interfaces to associated processes, especially of production planning and product development, within the prototype phase as well as to previous and subsequent product lifecycle phases.

In this context efficient and effective mean: doing the right process activities for detecting quality deviations as well as initiating the development of measures (effective) and realizing them quickly at the right time within the prototype phase (efficient) [cf. 20].

Presenting an approach for the development of such a quality control loop including a quality process with the described interfaces to associated processes in product development, production planning and $\mathrm{QM}$ as well as a first examination of the 
affected process parts especially in production planning is subject of this paper to answer the main research question:

How should a cycle oriented QM during the prototype phase be designed leveraging and improving the interface especially to production planning?

The remainder of this article is structured as follows: Specification of the intended result of the research activities in chapter 2, followed by an explanation of the proposed scientific approach in chapter 3 and a comprehensive summary and outlook in chapter 4 .

\section{Indented Results of the Approach for Quality Management in the Prototype Phase}

Achieving a sufficiently high prototype quality at the end of the prototype phase which is close to the required quality during mass-production is a key lever for reducing the amount of required adaptations and changes of the product as well as of production structure, processes and manufacturing resources during mass-production phase. An efficient and effective quality control loop is an important enabler for this purpose.

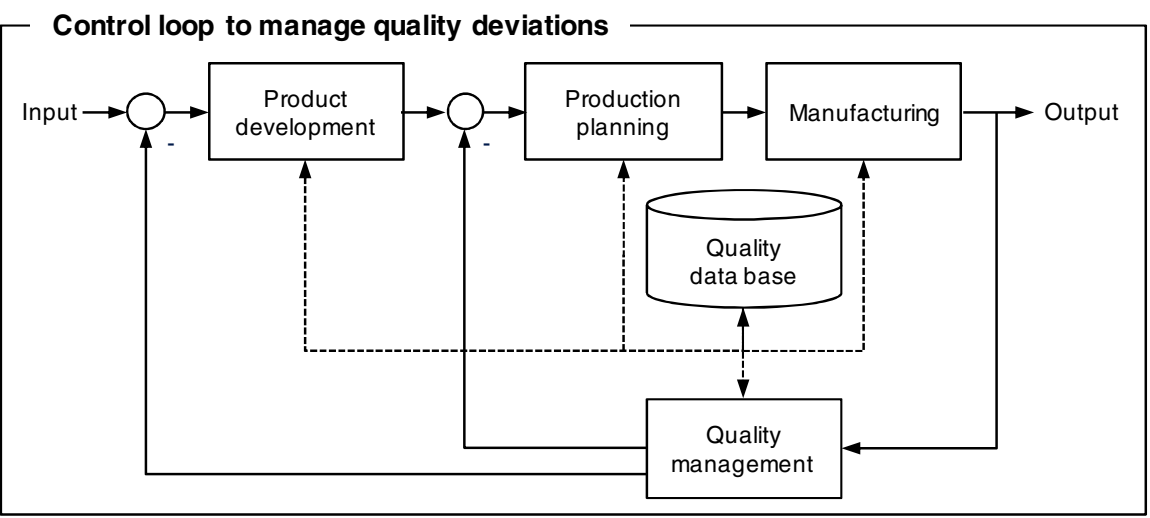

Fig. 4. Quality control loop to manage quality deviations [cf. 19]

The QM process to be developed focuses on the prototype phase while also taking the overall product lifecycle into consideration. That means, the QM process cannot be a stand-alone process but possesses distinct interfaces to production planning, product development and the overall quality management (see fig. 4). The QM process which can be understood as a cycle has to be segmented in specific phases with defined triggers for each phase, so that process activities, such as series of measurements or alignment meetings, can be clearly allocated, interfaces established and the QM cycle managed.

Within the specific phases, a deviation measurement concept has to be defined for testing of prototype quality. This concept covers not only required measurement 
points and frequencies but also procedures for identification and classification of deviations as well as for evaluation of potential influences and should be variable over time to meet the specific requirements of the prototype phase [cf. 3].

Based on the defined phases, triggers and the embedded deviation measurement concept, the interfaces between QM, product development and production planning act as connectors enabling an information exchange and close the quality control loop. For an efficient and effective implementation the interfaces should support a fast analysis of potential findings from deviation measurements and an aligned initiation of required measures. In practice, that could concretize e.g. in changes of product specifications or adaptations of manufacturing resources. [21]

Summarizing, the quality control loop with the QM process, the embedded deviation measurement concept and the specific interfaces provide the basis for improvements in prototype quality and later reductions of non-conformance costs during mass-production phase.

\section{Scientific Approach}

The definition and evaluation of a quality control loop for the prototype phase will be based on five work packages. The approach presented in this article covers the analysis of the state-of-the-art, the definition of a quality control loop and QM process based on accepted QM approaches (compare e.g. [18], a measurement concept and the elaboration of specific process interfaces (see fig. 5).

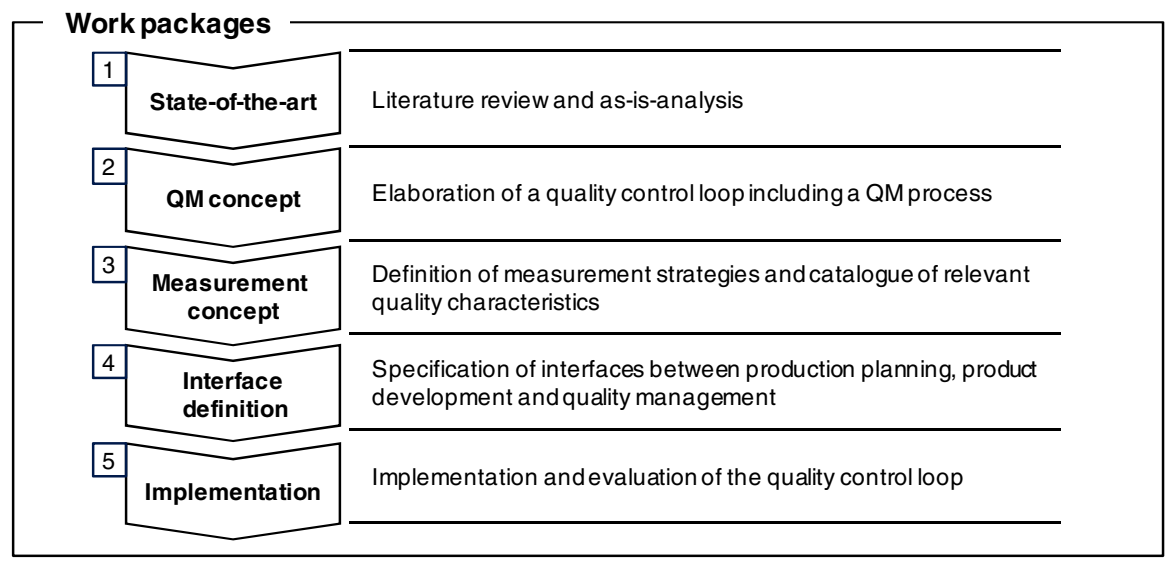

Fig. 5. Five-step-approach for the development of the quality control loop

State-of-the-Art. First, the state-of-the-art regarding product lifecycles, quality control loops, QM processes and processes for production planning with focus on interfaces to quality management will be prepared based on both, a comprehensive literature review and examples for "as-is approaches" from automotive industry. 
QM Concept. Proceeding from the state-of-the-art, a general concept for a quality control loop for the prototype phase will be elaborated. This concept should comprise not only the overall description of the quality control loop but also a more detailed definition of the QM process. This requires a distinction of relevant phases within the QM process and within the quality control loop. Further, triggers for the different phases and their potential dependencies should be specified.

Measurement Concept. Third step is the definition of a deviation measurement concept as part of the QM process. This measurement concept should cover both, measurement strategies specifying when and where measurements are required and also a catalogue for measurement characteristics including e.g. measuring points, tolerances and relevance of the respective characteristic. Subsequently, this concept should be embedded in the QM process.

Interface Definition. In the following fourth step, interfaces to the processes of production planning and product development as well as the overall quality management process should be specified. That includes a detailed analysis and elaboration of potential localizations and properties of the interfaces as well as the integration of processes based on plausible scenarios. These scenarios account for the necessity of e.g. regular adaptations of manufacturing resources or processes on the one hand and "fast-track" adaptations of those on the other hand (see fig. 3). For this, process integrated approaches and methods such as design reviews or quality gates need to be considered.

Following, parts of the production planning process relevant for the interfaces should be analyzed to identify potential modifications for an adapted production planning process with respect to occurring quality deviations during the prototype phase. In addition, same has to be performed regarding product development processes, indicating an area for future research.

Implementation. In the fifth step the overall quality control loop should be implemented and evaluated. That comprises not only the practical application of the concept but also a critical concept review with regard to the defined QM process, the deviation measurement concept and the specified interfaces to product development and production planning.

\section{$4 \quad$ Summary and Outlook}

Product lifecycles are influenced by quality during all lifecycle phases. The earlier quality deviations are identified and the causes eliminated, the higher the positive impact on quality and potentially occurring non-conformance costs especially during mass-production. Hence, this article focuses on the analysis of quality management during the prototype phase and an approach for the development of an efficient and effective quality control loop. This includes the elaboration of a quality process with relevant interfaces to connected processes in product development, production 
planning and overall quality management as well as the specification of a deviation measurement concept as an embedded part of the QM process. The defined quality control loop enables an efficient and effective quality management during the prototype phase as well as connected previous and subsequent product lifecycle phases. This happens by reducing quality deviations occurring in the prototype phase and overall non-conformance costs during consecutive lifecycle phases such as the massproduction phase. Defining and establishing relevant interfaces between the quality process, the product development process or the production planning process prepares the basis for a comprehensive consideration of quality influences within production planning.

Besides quality, other influencing factors such as production quantities or manufacturing technology lifecycles impact the production planning but are rarely taken into account today [22]. Taking these often cyclic influences into consideration in the production planning process could significantly improve this process regarding required time, costs and quality. Today, existing production planning methods focus on the overall factory layout, production networks and the operative planning of the manufacturing task. However, a comprehensive planning method for the reconfiguration of manufacturing resources and the production structure involving cyclic influences such as quality, product changes or technology lifecycles is not available yet.

The approach presented in this article addresses one specific section of the aforementioned exemplary influences - quality - in relation with production planning. Next steps are the elaboration of the outlined quality control loop, the QM process, the deviation measurement concept and the required interfaces based on the proposed five-step approach (cf. chapter 3). In addition, a first examination of the affected process parts especially in production planning is to be carried out.

Future research activities will address the development and evaluation of comprehensive methods for production planning with a focus on reconfigurations of manufacturing resources and production structures, taking cyclic influences into consideration. The approach presented in this paper is a first step in this direction.

Acknowledgments. The German Research Foundation (DFG) funds this research and development project. We extend our sincere thanks to the DFG for the generous support of the work described in this paper, resulting from the subproject B5 "Design of changeable production resources" in the framework of the Collaborative Research Centre 768 "Managing cycles in innovation processes - Integrated development of product service systems based on technical products". The goal of the Collaborative Research Centre 768 is to reduce the knowledge gap regarding cycles and cyclic influences within the innovation process.

\section{References}

1. Brissaud, D., Tichkiewitch, S.: Product Models for Life-Cycle. Annals of the CIRP 50(1), 105-108 (2001)

2. Fleischer, J., Lanza, G., Ender, T.: Prozessinnovation durch prozessbasierte Qualitätsprognose im Produktionsanlauf. Zeitschrift für wirtschaftlichen Fabrikbetrieb, vol. 100. Carl Hanser, München (2005) 
3. Winkler, H.: Modellierung vernetzter Wirkbeziehungen im Produktionsanlauf. Leibniz Universität Hannover, Garbsen (2007)

4. Wiendahl, H.P., Reichardt, J., Nyhuis, P.: Handbuch Fabrikplanung - Konzept, Gestaltung und Umsetzung wandlungsfähiger Produktionsstätten. Hanser, München (2009)

5. Boehm, B.W.: Software engineering economics, Englewood Cliffs, NJ. Prentice-Hall Advances in Computing Science \& Technology Series (1981)

6. Clark, K.B., Fujimoto, T.: Product Development Performance. Strategy, organization and management in the world of auto industries. Harvard Business School Press, Boston (1991)

7. Feigenbaum, A.V.: Total Quality Control. McGraw-Hill, New York (1991)

8. Harrington, H.J.: Poor-Quality Cost. Society for Quality. Marcel Dekker Inc., New York (1987)

9. Nau, B.: Anlauforientierte Technologieplanung zur Auswahl von Fertigungstechnologien. RWTH Aachen, Apprimus, Aachen (2012)

10. Cooper, R.G.: Stage-gate systems: A new tool for managing new products. Business Horizons, Ontario 33 (1990)

11. Nada, O.A., ElMaraghy, H.A., ElMaraghy, W.H.: Quality Prediction in Manufacturing System Design. Journal of Manufacturing Systems 25(10), 293-314 (2006)

12. Scheer, A.W., Boczanski, M., Muth, M., Schmitz, W.G., Segelbacher, U.: Prozessorientiertes Product Lifecycle Management. Springer, Berlin (2006)

13. Schmidt, R.: The implementation of simultaneous engineering in the stage of product concept development: A process orientated improvement of quality function deployment. European Journal of Operational Research 100(10), 293-314 (1997)

14. Regius, B.: Qualität in der Produktentwicklung. Carl Hanser Verlag, München (2006)

15. Koren, Y., Heisel, U., Jovane, J., Moriwaki, T., Pritschow, G., Ulsoy, G., Van Brussel, H.: Reconfigurable Manufacturing Systems. Annals of the CIRP 48(2), 527-540 (1999)

16. Syska, A.: Produktionsmanagement. Gabler, Wiesbaden (2006)

17. Cheng, B.W., Maghsoodloo, S.: Optimization of Mechanical Assembly Tolerances by Incorporating Taguchi's Quality Loss Function. Journal of Manufacturing Systems 14(4), 264-276 (1995)

18. Hering, E., Triemel, J., Blank, H.-P.: Qualitätsmanagement für Ingenieure. Springer, Heidelberg (2003)

19. Westkämper, E.: Qualitätsmanagement in der Produktion. In: Eversheim, W., Schuh, G. (eds.) Produktion und Management: Betriebshütte. Springer, Berlin (2000)

20. Drucker, P.F.: Managing for Business Effectiveness. Harvard Business Review (1963)

21. Fricke, E., Gebhard, B., Negele, H., Igenbergs, E.: Coping with Changes: Causes, Findings, and Strategies. System Engineering 3(4), 169-179 (2000)

22. Zaeh, M.F., Reinhart, G., Karl, F., Schindler, S., Pohl, J., Rimpau, C.: Cyclic influences within the production resource planning process. Production Engineering - Research and Development 4, 309-317 (2010) 